\title{
Multivalent Fusion DNA Vaccine against Brucella abortus
}

\author{
Leonardo Gómez, Javiera Llanos, Emilia Escalona, Darwin Sáez, Francisco Álvarez, \\ Raúl Molina, Manuel Flores, and Angel Oñate
}

\author{
Laboratory of Molecular Immunology, Department of Microbiology, Faculty of Biological Sciences, University of Concepción, \\ Concepción, Chile
}

Correspondence should be addressed to Angel Oñate; aonate@udec.cl

Received 18 April 2017; Revised 5 July 2017; Accepted 6 August 2017; Published 7 September 2017

Academic Editor: Bernd H. Rehm

Copyright ( $) 2017$ Leonardo Gómez et al. This is an open access article distributed under the Creative Commons Attribution License, which permits unrestricted use, distribution, and reproduction in any medium, provided the original work is properly cited.

\begin{abstract}
As an alternative brucellosis prevention method, we evaluated the immunogenicity induced by new multivalent DNA vaccines in BALB/c mice. We constructed the vaccines by fusion of BAB1_0273 and/or BAB1_0278 open reading frames (ORFs) from genomic island 3 (GI-3) and the Brucella abortus 2308 sodC gene with a link based on prolines and alanines (pV273-sod, pV278sod, and pV273-278-sod, resp.). Results show that immunization with all tested multivalent DNA vaccines induced a specific humoral and cellular immune response. These novel multivalent vaccines significantly increased the production of IgM, IgG, and IgG2a antibodies as well as IFN- $\gamma$ levels and the lymphoproliferative response of splenocytes. Although immunization with these multivalent vaccines induced a typical T-helper 1- (Th1-) dominated immune response, such immunogenicity conferred low protection levels in mice challenged with the B. abortus 2308 pathogenic strain. Our results demonstrated that the expression of BAB1_0273 and/or BABl_0278 antigens conjugated to SOD protein can polarize mice immunity to a Th1-type phenotype, conferring low levels of protection.
\end{abstract}

\section{Introduction}

Brucella spp. cause brucellosis, a globally distributed zoonosis infecting more than half a million people worldwide every year [1]. This genus is constituted by Gram-negative, coccobacillary, microaerophilic, non-spore-forming, immotile, intracellular facultative, and slow-growing bacteria [2]. Such pathogens are found in a wide range of mammalian hosts, such as B. abortus (bovine), B. melitensis (goats), and B. suis (pigs) which are the most pathogenic species within the genus for humans [2,3]. Infection with these bacteria usually occurs through ingestion of contaminated food or through contact with infected animals [4]. In animals, brucellosis produces abortions in females and infertility in males, whereas in humans it is manifested by an acute phase of undulating fever and a chronic phase associated with arthritis, orchitis, hepatitis, encephalomyelitis, and endocarditis $[5,6]$.

B. abortus is a pathogen highly adapted to the intracellular environment. Inside cells, there exist adverse conditions including acidic $\mathrm{pH}$, proteases, and reactive oxygen species (ROS) and reactive nitrogen species (RNS) [7]. The pathogen survives this hostile microenvironment by expressing $\mathrm{Cu}-\mathrm{Zn}$ superoxide dismutase (SOD) enzyme which detoxifies the superoxide radical $\left(\mathrm{O}_{2}^{-}\right)$transforming it into oxygen $\left(\mathrm{O}_{2}\right)$ and hydrogen peroxide $\left(\mathrm{H}_{2} \mathrm{O}_{2}\right)$ [8]. In addition, its traffic into the cells is carried out in a Brucella Containing Vacuole $(\mathrm{BCV})$, which interacts with early and lysosomal endosomes that acidify the $\mathrm{BCV}$, promoting the expression of several virulence factors, such as the VirB type IV secretion system (SST4) [3]. These factors allow it to avoid the phagolysosomal proteases and redirect its intracellular traffic to the endoplasmic reticulum, where it creates a replicative niche [9]. Among the molecules secreted by SST4 is the Btpl protein, which inhibits dendritic cell maturation [10]. This protein is encoded in B. abortus BAB1_0279 open reading frame (ORF) of genomic island 3 (GI-3). This GI in B. abortus 2308 includes the ORF BAB1_0250 to BAB1_0279 and contains 25 genes, many of which have unknown function, and several pseudogenes [11].

Current vaccines used to prevent brucellosis depend on live attenuated B. abortus RB51 and S19 strains [12]. These vaccines have been effective in controlling the disease; 
however, they may cause abortions in immunized animals and are pathogenic for humans [13]. An alternative for the development of effective and safe vaccines can be achieved by the immunization with DNA, a vaccinal strategy inducing T-helper type 1 (Th1) immune responses associated with IFN $-\gamma$ producing $\mathrm{CD} 4+\mathrm{T}$ and cytotoxic $\mathrm{CD} 8+\mathrm{T}$ cells and IgG2a antibody produced by $\mathrm{B}$ cells, required to clear $B$. abortus infection [14]. In addition, DNA vaccines allow expression of individual antigens, fused multiple antigens, or immunodominant epitopes from each antigen to enhance vaccine immunogenicity [15-17]. Among the antigens used for the development of DNA vaccines against brucellosis are BAB1_0278 and BAB1_0273 ORFs. BAB1_0278 encodes a hypothetical GrcA protein involved in the cell cycle, whose deletion affects the efficiency of bacterial growth within phagocytes and its virulence [18], and a DNA vaccine codifying this ORF showed to efficiently induce an immune response and protection $[19,20]$. On the other hand, BAB1_0273 is a possible DNA-binding protein, exhibiting immunodominant epitopes used to design and to evaluate a multiple epitope DNA vaccine, which showed to be immunogenic and to confer protection in the murine model [21]. Furthermore, it has been shown that peptides of the $\mathrm{Cu}-\mathrm{Zn}$ superoxide dismutase protein $(\mathrm{Cu} / \mathrm{Zn} \mathrm{SOD})$ are immunodominant and a DNA vaccine encoding the sodC gene $(\mathrm{Cu}-\mathrm{Zn}$ SOD) provides protection [17, 22].

Therefore, due to the immunogenic characteristics reported for the BAB1_0273, BAB1_0278, and the sodC genes, we designed three multivalent DNA vaccines based on the BAB1_0273 and/or BAB1_0278 ORFs fused with the sodC gene from $B$. abortus, with the aim of evaluating their efficiency to induce an effective immune response against brucellosis.

\section{Materials and Methods}

2.1. Animals. Eight-week-old BALB/c female mice were provided by the Instituto de Salud Publica, Santiago, Chile. Animal maintenance was carried out in the Molecular Immunology Laboratory (Department of Microbiology, Faculty of Biological Sciences, University of Concepción), where they were fed with water and food "ad libitum." Management of these animals was carried out in accordance with the regulations of the Bioethics and Safety Committee of the Faculty of Biological Sciences, University of Concepción regulations. All efforts were made to minimize animal suffering.

\subsection{Design and Construction of Multivalent DNA Vaccines.} Vaccines were constructed using BAB1_0273 and BAB1_0278 ORFs and the sodC gene from B. abortus 2308, according to nucleotide sequences available from GenBank (WP 002965521.1, WP_002965527.1, and WP_002972093.1, resp.). We used three different gene combinations: BAB1_0273sod, BAB1_0278-sod, and BAB1_0273-278-sod. Genes were fused using a rigid linker based on a proline and alanine sequence (PAPAP) [23]. The chimeric multivalent genes were chemically synthesized by GenScript, Inc. (Piscataway, NJ, USA), with codon optimization for mouse and Escherichia coli. These sequences were cloned in the Pst $\mathrm{I}$ and BamHI restriction sites into the pVAX1 vector (Thermo Fisher Scientific Inc., MA, USA) and linked with the T4 ligase enzyme (New England Biolabs, Inc., MA, USA). Resulting constructs were named pV273-sod, pV278-sod, and pV273-278-sod, and their construction was successfully performed and visualized in $1 \%$ agarose gels. DNA required for all immunizations were obtained by electroporation of the E. coli $\mathrm{DH} 5 \alpha$ strain with each of these vectors and cultured in Terrific Broth (TB) supplemented with $50 \mu \mathrm{g} / \mathrm{ml}$ kanamycin during $18 \mathrm{~h}$ at $37^{\circ} \mathrm{C}$. Subsequently, the vectors were purified using the alkaline lysis procedure [24]. The final concentrations of the recombinant DNAs (pV273-sod, pV278-sod, and pV273-278sod) were quantified using the Infinite ${ }^{\circledR} 200$ PRO NanoQuant kit (Tecan Group Ltd., Switzerland) and adjusted to the concentrations required for each immunization.

\subsection{Expression and Purification of Recombinant Proteins.} Multivalent recombinant proteins (MVRPs) encoded by BAB1_0273-sod, BAB1_0278-sod, and BAB1_0273-278-sod genes were purified cloning these sequences in the prokaryote pQe80L (Addgene, MA, USA) expression vector: pQ273s, pQ278s, and pQ273-278s. Later, E. coli BL21 (DE3) strain was transformed with these vectors to express the recombinant proteins, inducing their expression with $0.2 \mathrm{mM}$ isopropyl thiogalactopyranoside (IPTG) for $4 \mathrm{~h}$ at $25^{\circ} \mathrm{C}$. Subsequently, bacteria were resuspended in phosphate buffered saline (PBS) with $0.2 \mathrm{mM}$ phenylmethylsulfonyl fluoride (PMSF) and sonicated for $10 \mathrm{~min}$ (70\% amplitude with 30 second pulses) on ice. Proteins were detected in the soluble phase and purified by histidine affinity chromatography using HisTrap FF crude columns (GE Healthcare, UK). Recombinant protein purification was visualized by $12 \%$ sodium dodecyl sulfate polyacrylamide gel electrophoresis (SDS-PAGE) and confirmed with a western blot using $6 \mathrm{x}$ anti-His antibodies (Abcam, Cambridge, UK). These recombinant proteins will be hereon named R273S, R278S, and R273-278S, respectively. Proteins were quantified using the Pierce ${ }^{\mathrm{TM}}$ BCA Protein Assay kit (Thermo Fisher Scientific Inc., MA, USA) using Bovine Serum Albumin (BSA) as the standard.

2.4. Immunizations. Mice were randomly separated into negative control (PBS and pVAX) and experimental (pV273-sod, pV278-sod, and pV273-278-sod) groups with five animals per group. In the case of immunization with a DNA-type vaccine, each animal received a $100 \mu \mathrm{g}$ dose of recombinant DNA in $100 \mu \mathrm{l}$ of PBS, divided into two injections of $50 \mu \mathrm{l}$ in each posterior tibialis muscle. The PBS negative control received $100 \mu \mathrm{l}$ of PBS, injected as described above for the experimental group. All animals received three immunizations at 15-day intervals [25].

2.5. Production of Antibodies. Antibody production was quantified from the peripheral blood of mice obtained at 0 , 15,30 , and 45 days after immunization using the indirect ELISA method [25]. For this, 96-well plates (Nunc Maxisorp, Thermo Fisher Scientific, MA, USA) were coated with $5 \mu \mathrm{g}$ of recombinant proteins per milliliter of carbonate-bicarbonate buffer $(50 \mathrm{mM}, \mathrm{pH} 9.6)$ and incubated for $16 \mathrm{~h}$ at $4^{\circ} \mathrm{C}$ in a humidity chamber. Plates were washed with TPBS buffer 
(PBS plus $0.05 \%$ Tween 20 ) and blocked with $0.8 \%$ gelatin for $1 \mathrm{~h}$ at $37^{\circ} \mathrm{C}$ in order to avoid nonspecific binding. To each well, $100 \mu \mathrm{l}$ of serum was added in serial dilutions using TPBS plus $0.2 \%$ gelatin, starting at 1:200 dilutions. Samples were incubated for $3 \mathrm{~h}$ at $37^{\circ} \mathrm{C}$. After this time, rabbit anti-mouse IgM, IgG, IgG1, or IgG2a secondary antibodies conjugated with horseradish peroxidase (Serotec, Oxford, UK) diluted 1:1000 were added and incubated for $45 \mathrm{~min}$ at $37^{\circ} \mathrm{C}$. The reaction was revealed with $100 \mu$ l SigmaFast (Sigma-Aldrich, St. Louis, MO, USA) OPD. The final reaction was stopped with $50 \mu \mathrm{l}$ of sulfuric acid $2 \mathrm{~N}$ and read at $490 \mathrm{~nm}$ using a VictorX3 microplate reader (PerkinElmer, USA). Results were expressed as mean \pm standard deviation $(\mathrm{SD})$ of the inverse from the last dilution reached before the cut-off. All experiments were done in triplicate.

2.6. Lymphoproliferation Assay. Mice were sacrificed thirty days after the last immunization and their spleens were extracted under aseptic conditions to be homogenized in RPMI 1640 (Gibco) medium [25]. Cells were adjusted to a concentration of $4 \times 10^{6}$ viable cells/ml in RPMI medium supplemented ( $10 \%$ heat inactivated fetal bovine serum plus $50 \mathrm{IU} / \mathrm{ml}$ penicillin, $50 \mu \mathrm{g} / \mathrm{ml}$ streptomycin, and $0.25 \mu \mathrm{g} / \mathrm{ml}$ amphotericin B) and cultured (100 $\mu \mathrm{l}$ per well) in 96-well microtiter plates (Nunc, Denmark), previously sensitized with 2 or $10 \mu \mathrm{g} / \mathrm{ml}$ recombinant proteins or crude $B$. abortus RB51 proteins (CBPs), respectively, for $72 \mathrm{~h}$ at $37^{\circ} \mathrm{C}$ and $5 \%$ $\mathrm{CO}_{2}$. CBPs were obtained from $60 \%$ methanol inactivated Brucella subjected to a treatment with a hypertonic salt solution ( $1 \mathrm{M} \mathrm{NaCl}$ and $0.1 \mathrm{M}$ sodium citrate) for $24 \mathrm{~h}$; then the bacterial suspension was subjected to sonication for 20 minutes and centrifuged to obtain the supernatant [26]. After culturing, splenocytes were pulsed with $0.5 \mu \mathrm{Ci}$ tritiated thymidine $\left({ }^{3} \mathrm{H}\right.$-TdR) per well (Amersham, Life Science, London, UK) and $8 \mathrm{~h}$ later radioactivity incorporated into the DNA was measured using a scintillation counter (Beckman LS 6500, USA). As a lymphoproliferation positive control, $10 \mu \mathrm{g} / \mathrm{ml}$ of concanavalin A (Promega, Madison, WI, USA) was used, while complete RPMI 1640 was used as a negative control. All experiments were done in triplicate.

2.7. Cytokines Levels. The levels of IFN- $\gamma$ and IL-4 secreted were quantified from the supernatant of splenocytes cultures by antigen-capture ELISA. For this, $10^{6}$ splenocytes $/ \mathrm{ml}$ were cultured in 24 wells plates (Nunclon, Denmark) previously sensitized with 2 or $10 \mu \mathrm{g} / \mathrm{ml}$ of recombinant proteins for $72 \mathrm{~h}$ at $37^{\circ} \mathrm{C}$ with $5 \% \mathrm{CO}_{2}$. Aliquots from each well were then taken and IFN- $\gamma$ and IL-4 levels were measured using the Ready-SET-Go! ELISA kit (eBioscience, Thermo Fisher Scientific, MA, USA) following the manufacturer's instructions. Final cytokine concentrations were calculated using standard curves for recombinants IFN- $\gamma$ and IL-4 (eBioscience, Thermo Fisher Scientific, MA, USA). The final reaction was read at $490 \mathrm{~nm}$ on a VictorX3 ELISA reader instrument (PerkinElmer, USA). All experiments were done in triplicate.

2.8. Protection Experiment. Thirty days after the last immunization, mice were challenged by intraperitoneal injection with $B$. abortus 2308 at a dose of $10^{4}$ colony-forming units
(CFU) per animal. The positive control corresponded to a group of mice immunized with $1 \times 10^{8} \mathrm{CFU}$ of the $B$. abortus RB51 vaccine strain. After fifteen days, all mice were euthanized and their spleens removed. Spleens were homogenized in PBS, serially diluted, and cultured in Petri dishes containing agar Columbia supplemented with 5\% sheep blood (bioMérieux, Santiago, Chile) for $72 \mathrm{~h}$ at $37^{\circ} \mathrm{C}$. Finally, the number of CFU per spleen was calculated and reported as units of protection represented by the reduction of mean \pm $\mathrm{SD}$ of $\log _{10} \mathrm{CFU} /$ spleen relative to the PBS group [17].

2.9. Statistical Analysis. Antibody production, levels of cytokines, and lymphoproliferative response were analyzed by two-way ANOVA, while the protective response was analyzed with a one-way ANOVA. Multiple comparisons were made using the Tukey test. Data analyses were performed using the GraphPad Prism 5.0 statistical program. A $P$ value of 0.05 or less was considered statistically significant.

\section{Results}

3.1. Construction of Multivalent DNA Vaccines and Recombinant Products Purification. The multivalent DNA vaccines were successfully constructed cloning the sequences BAB1_0273-sodC (768 bp), BAB1_0278-sodC (1071bp), and BAB1_0273-278-sodC (1329 bp) into pVAX1 vector (3000 bp) multicloning site, using Pst I and BamHI restriction enzymes (see Figure S1 in Supplementary Material available online at https://doi.org/10.1155/2017/6535479). The recombinant vectors pV273-sod, pV278-sod, and pV273-278-soC were used to induce a specific immune response of $\mathrm{BALB} / \mathrm{c}$ mice against recombinant antigens codified in these multivalent DNA sequences. The recombinant proteins R273S (27.8 kDa), R278S (40 kDa), and R273-278S (49.3 kDa) were expressed in E. coli BL21 (DE3) transformed with the plasmids pQ273s, pQ278s, or pQ273-278s (Figure S2A). All recombinant proteins were tagged with $6 \mathrm{x}$ His and visualized by western blot (Figure S2B).

3.2. Production of Antibodies. Titers of IgM, IgG, IgG1, and IgG2a serum antibodies were measured by ELISA from mice immunized with multivalent DNA vaccines pV273sod, $\mathrm{pV} 278$-sod, $\mathrm{pV} 273$-278-sod, $\mathrm{pVAX}$ vector or control PBS. Sera of mice 30 days after immunization with different multivalent DNA vaccines achieved a significantly level of anti-recombinant $\operatorname{IgM}(P<0.05)$. The levels of specific $\operatorname{IgM}$ decreased at day 45 but were still significantly greater than the PBS and pVAX control groups $(P<0.05)$ (Figure 1(a)). Mice immunized with pV273-sod, pV278-sod, or pV273-278sod had significantly increased titers of the specific IgG at days 15 and 30 after immunization when compared to pVAX and PBS control groups, these levels being higher in the group immunized with the trivalent $\mathrm{pV} 273-278$-sod vaccine $(P<0.001)$. Significant levels of type-IgG antibodies were observed in sera from immunized animals with pV278-sod vaccines at day 45 after immunization $(P<0.01)$, where response on this same day was low and not significant when compared to mice immunized with the other DNA vaccines under study (Figure 1(b)). When evaluating IgG2a levels, it 


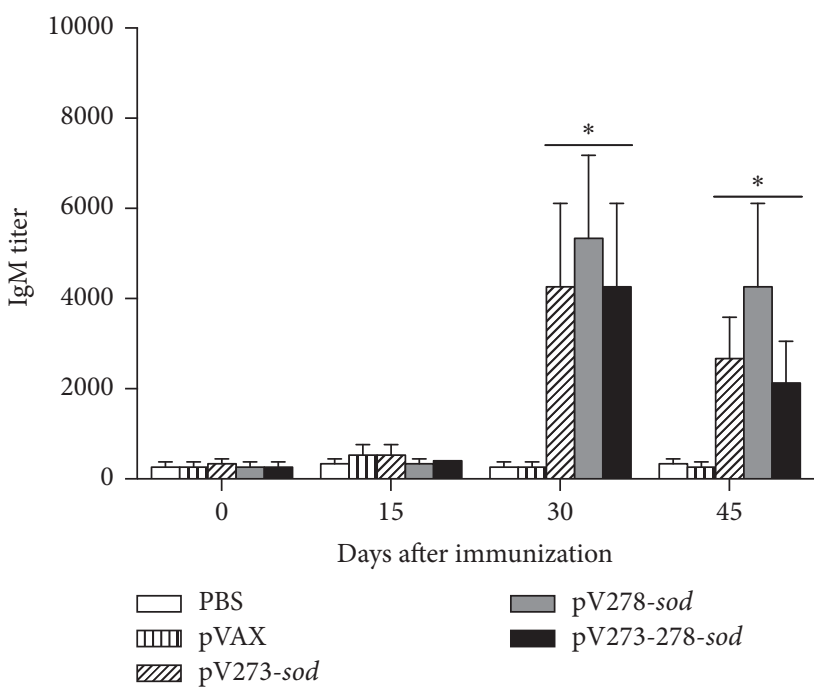

(a)

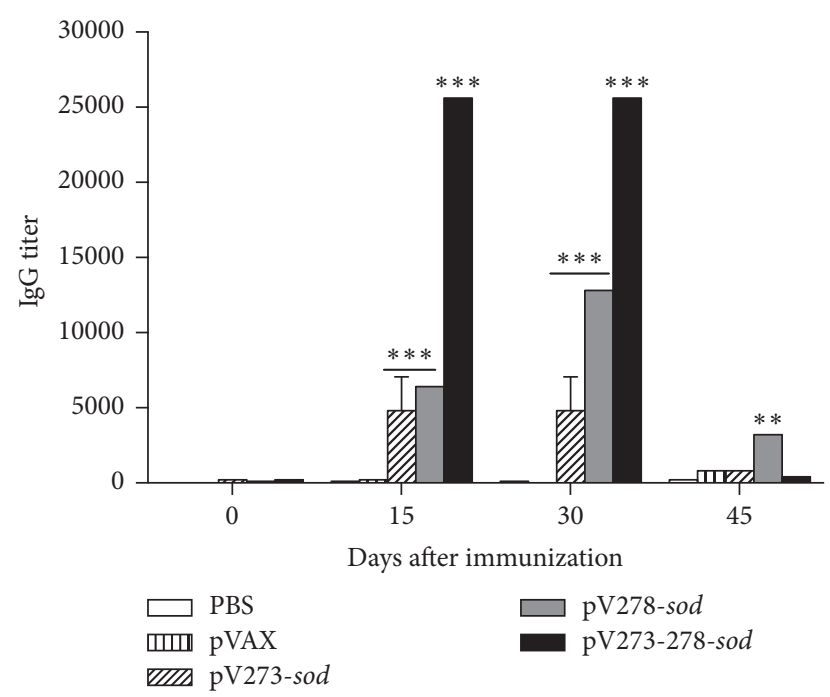

(b)

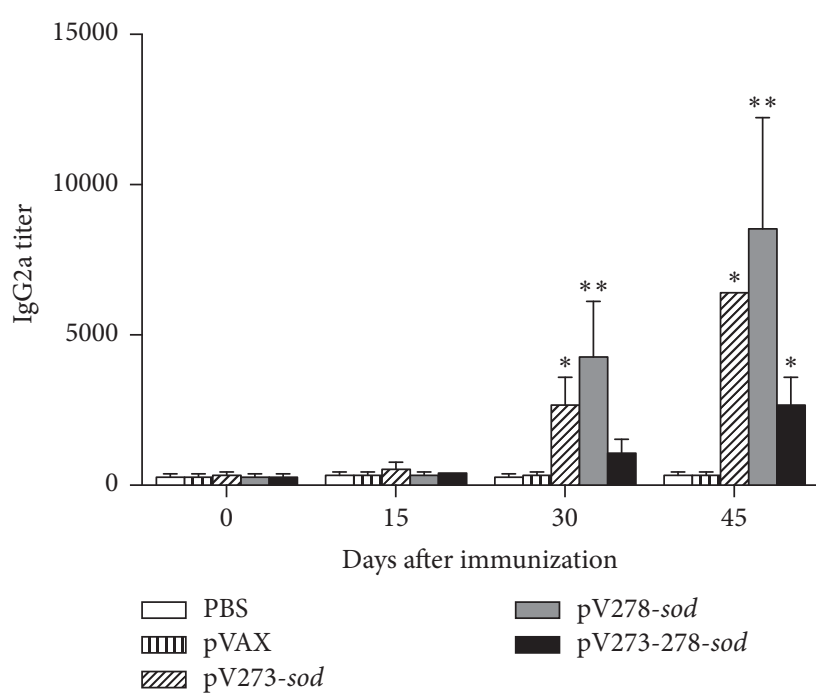

(c)

Figure 1: Peripheral blood antibody production quantified by indirect ELISA. (a) IgM, (b) IgG, and (c) IgG2a, specific against recombinant proteins. Results are plotted as mean \pm standard deviation of the inverse of the last dilution before cutting. ${ }^{*} P<0.05$, ${ }^{* *} P<0.01$, and ${ }^{* * *} P<0.001$ indicate statistically significant values.

was observed that the bivalent DNA vaccines pV273 and pV278-sod produced a significant increase of this antibody at day 30 following vaccination and the peak titers were detected at day 45 after immunization (end of experiment) $(P<0.05$ and $P<0.01$, resp.). Trivalent vaccine pV273-278sod produced a significant level of IgG2a only at day 45 after immunization $(P<0.05)$ (Figure $1(\mathrm{c})$ ). None of the studied animals inoculated with different DNA vaccines induced production of specific IgG1 (data not shown).

3.3. Lymphoproliferative Response. Results showed that splenocytes of mice immunized with pV278-sod or pV273278-sod vaccines proliferated significantly after being stimulated with $2 \mu \mathrm{g} / \mathrm{ml}$ of their respective recombinant proteins $(P<0.001)$, while $\mathrm{pV} 273$-sod vaccine did not induce differences compared to the control group $(P>0.05)$
(Figure 2(a)). Splenocytes from mice immunized with pV273-sod, pV278-sod, or pV273-278-sod vaccines had a significant T-cell proliferation response using $10 \mu \mathrm{g} / \mathrm{ml}$ of their respective recombinant proteins $(P<0.001)$ (Figure 2(a)). In vitro stimulation of splenocytes from mice immunized with pV273-sod or pV278-sod vaccines with $2 \mu \mathrm{g} / \mathrm{ml}$ of crude Brucella proteins (CBPs) significantly increased their cellular proliferation $(P<0.05)$. The proliferative response was more pronounced and significant when stimulating with $2 \mu \mathrm{g} / \mathrm{ml}$ of CBPs the splenocytes obtained from the group of animals immunized with the trivalent vaccine pV273-278-sod $(P<0.001)$ (Figure $2(\mathrm{a})$ ). On the other hand, when splenocytes from mice immunized with the pV273-sod, pV278-sod, or pV273-278-sod vaccines were stimulated in vitro with $10 \mu \mathrm{g} / \mathrm{ml}$ of CBPs they showed significant proliferation when compared to control groups 


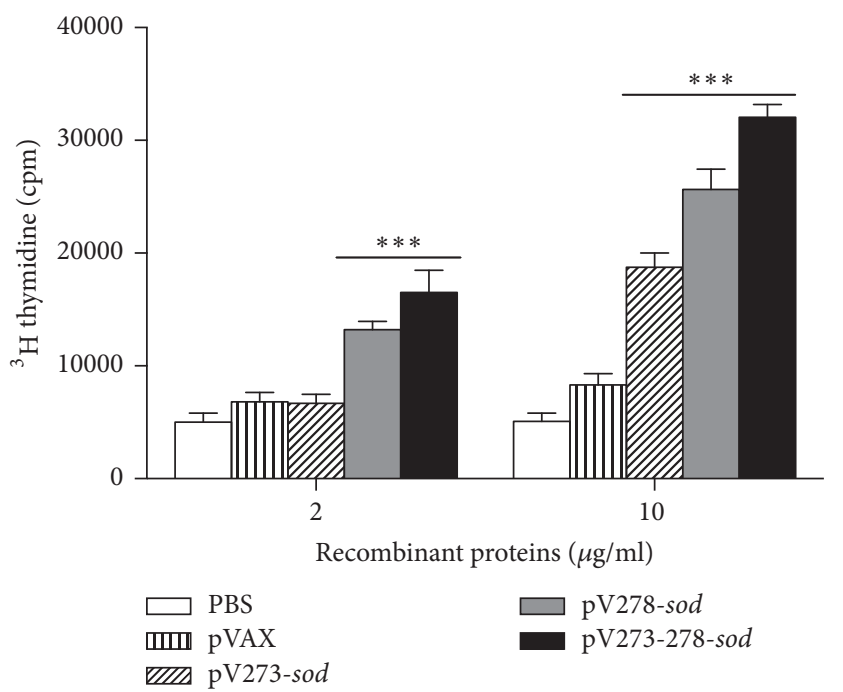

(a)

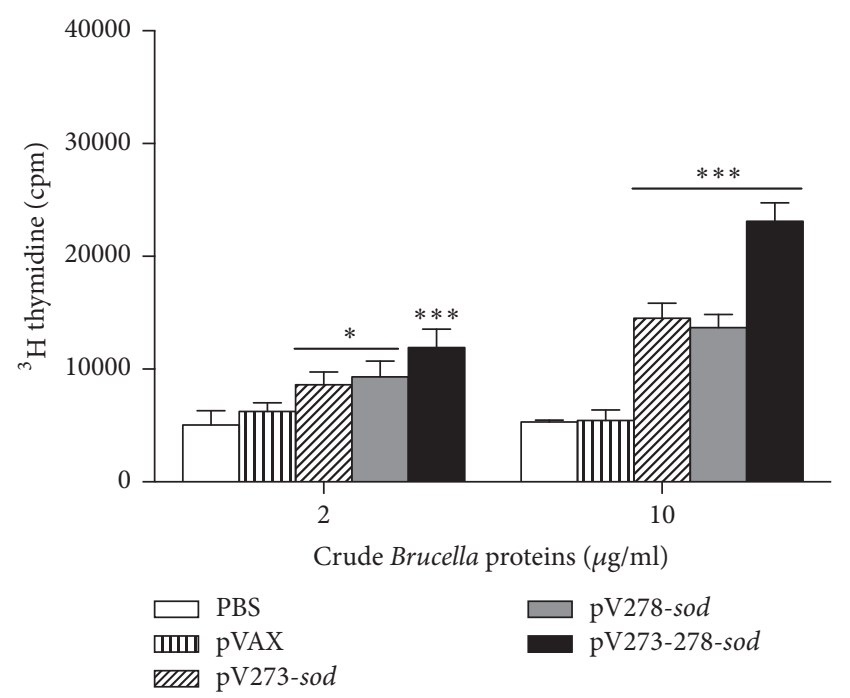

(b)

FIGURE 2: Lymphoproliferative response. Splenocytes stimulated in vitro with (a) $2 \mu \mathrm{g} / \mathrm{ml}$ or $10 \mu \mathrm{g} / \mathrm{ml}$ of R273S, R278S, or R273-278S recombinant proteins, respectively, and (b) $2 \mu \mathrm{g} / \mathrm{ml}$ or $10 \mu \mathrm{g} / \mathrm{ml}$ of B. abortus 2308 crude Brucella proteins. Results are plotted as mean \pm standard deviation. ${ }^{*} P<0.05$ and ${ }^{* * *} P<0.001$ indicate statistically significant values.

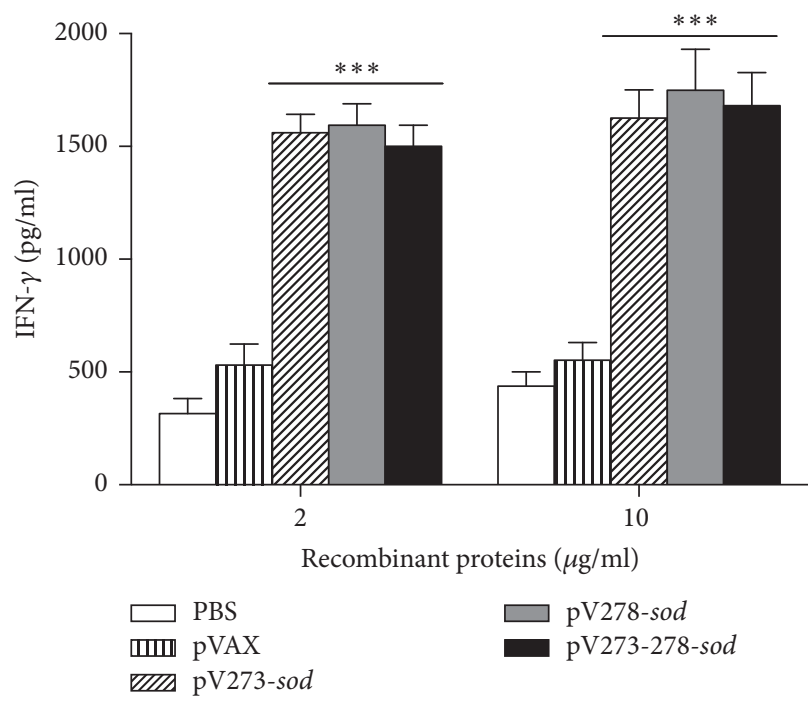

(a)

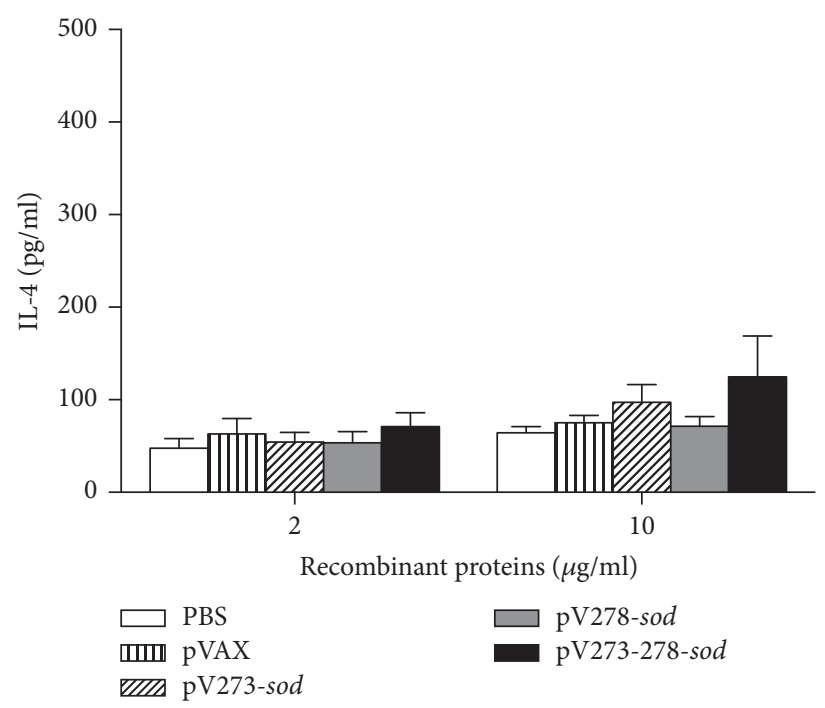

(b)

Figure 3: Cytokine levels quantified by ELISA sandwich. Production of (a) IFN- $\gamma$ and (b) IL-4, present in the supernatant of splenocytes stimulated in vitro with 2 or $10 \mu \mathrm{g} / \mathrm{ml}$ of R273S, R278S, or R273-278S recombinant proteins for $72 \mathrm{~h}$. Results are plotted as mean \pm standard deviation. ${ }^{* * *} P<0.001$ indicates statistically significant values.

$(P<0.001)$ (Figure 2(b)). The positive control $(10 \mu \mathrm{g} / \mathrm{ml}$ of ConA) showed a higher lymphoproliferative response than the experimental group (data not shown).

3.4. Levels of Cytokines. The Th1/Th2 response induced in the immunized mice was evaluated in vitro by the production of IFN- $\gamma$ and IL-4 in splenocytes stimulated with the respective recombinant proteins. Splenocytes from mice immunized with multivalent DNA vaccines $\mathrm{pV} 273$-sod, pV278-sod, or pV273-278-sod significantly increased IFN$\gamma$ production after being stimulated with 2 or $10 \mu \mathrm{g} / \mathrm{ml}$ of recombinant proteins, reaching highly significant $P$ values when compared to control groups PBS and $\operatorname{pVAX}(P<0.001)$ (Figure 3(a)). In vitro stimulation of splenocytes with 2 or $10 \mu \mathrm{g} / \mathrm{ml}$ recombinant proteins did not produce a significant increase in IL-4 production (Figure 3(b)).

3.5. Protective Response. The protective response was quantified by the ability of the immunized mice to eliminate the B. abortus 2308 pathogenic strain from the spleen. Results showed that immunization with the pV273-sod vaccine reduced the CFU by $\log _{10} 0.4$ when compared to the PBS 
TABLE 1: Protection conferred by multivalent DNA vaccines in BALB/c mice challenged with the pathogenic B. abortus 2308 strain.

\begin{tabular}{lcc}
\hline Experimental groups $(n=5)$ & $\log _{10}$ CFU of Brucella abortus 2308 per spleen (means \pm SD) & $\log _{10}$ units of protection $^{\mathrm{a}}$ \\
\hline PBS & $4.98 \pm 0.09$ & 0 \\
pVAX & $4.92 \pm 0.06$ & 0 \\
pV273-sod & $4.58 \pm 0.07$ & 0.40 \\
pV278-sod & $4.66 \pm 0.18$ & 0.32 \\
pV273-278-sod & $4.7 \pm 0.23$ & 0.28 \\
B. abortus strain RB51 & $4.04 \pm 0.25$ & $0.94^{*}$ \\
\hline
\end{tabular}

${ }^{a}$ Units of protection represent the difference between the mean \pm SD of $\log _{10}$ CFU values of the PBS control group and log 10 CFU values of the immunized group. All animals were challenged with $B$. abortus 2308 strain and bacterial counts were assessed at day $15 .{ }^{*} P<0.05$ indicates statistically significant values..

injected group. Meanwhile, immunization with the pV278sod and pV273-278-sod vaccines reduced the CFU by $\log _{10}$ 0.32 and 0.28 , respectively, when compared to the PBS group. These results are not statistically significant $(P>0.05)$ when compared to the PBS control group. The positive control group reduced the CFU by $\log _{10} 0.94(P<0.05)$. Results showed that the three multivalent DNA vaccines conferred lower levels of protection against the pathogenic B. abortus 2308 strain (Table 1).

\section{Discussion}

In order to obtain a safer vaccine against brucellosis, immunization with DNA vectors has been implemented due to their ability to induce the generation of a Thl-type immune response, which is protective against $B$. abortus $[14,27,28]$. This response can be induced by immunization, allowing its rapid activation at the time of infection with Brucella, where its immunogenic antigens are processed and presented to T cells [29]. DNA immunization using BAB1_0278 ORF $[19,20]$, immunodominant epitopes of BAB1_0273 ORF [21], and $\mathrm{Cu}-\mathrm{Zn}$ superoxide dismutase gene $(\operatorname{sod} C)$ [17] appeared to be highly immunogenic and capable of conferring high levels of protection in mice challenged with pathogenic strain B. abortus 2308. Based on this background, we built the multivalent DNA vaccines pV273-sod, pV278-sod, and pV273-278-sod by combining BAB1_0273 or/and BAB1_0278 ORFs to the $B$. abortus sod $C$ gene in order to examine whether these vaccine designs can induce an effective protective immune response against pathogenic strain B. abortus 2308 in $\mathrm{BALB} / \mathrm{c}$ mice.

The immunization with these multivalent DNA vaccines activated humoral and cellular immune responses in mice. Humoral immunity was quantified by the production of serum IgM, IgG, IgG1, and IgG2a antibodies. All multivalent vaccines induced a significant increase of specific IgM and IgG antibodies response that decays over time, the trivalent vaccine pV273-278-sod being the one producing the highest titer of specific IgG antibody. Levels of different IgG isotypes showed a predominant production of IgG2a in mice immunized with the three vaccines. IgG2a is produced by plasma cells in the presence of IFN- $\gamma$ [30], a cytokine associated with an efficient protection against intracellular pathogens, such as Brucella [31]. This isotype promotes phagocytosis of Brucella, accelerating phagosome maturation and activating a wide range of antimicrobial responses in phagocytic cells [14]. This response allows the elimination of phagocytized bacteria followed by the activation of cellular immune responses through the presentation of antigens, costimulatory proteins, and cytokines [28]. Although these antibodies activate several host protective mechanisms, opsonization of $B$. abortus facilitates pathogen entry into the cells, an environment in which it is highly adapted to survive $[32,33]$.

Immune mechanisms allowing removal of $B$. abortus from infected cells depend on Th1-type cellular immunity $[14,28]$. This response was quantified in vitro by the lymphoproliferative response of T cells and IFN- $\gamma$ levels produced by splenocytes stimulated with recombinant antigens. Results demonstrated that the splenocytes derived from mice immunized with any of the vaccines proliferated significantly when stimulated with the respective recombinant protein or CBPs (2 or $10 \mu \mathrm{g} / \mathrm{ml}$, resp.). Moreover, splenocytes from mice immunized with any of the three DNA vaccines and stimulated with the respective recombinant protein induced IFN- $\gamma$ production, a fundamental cytokine in host resistance against brucellosis $[31,34]$. IFN- $\gamma$ produces pleiotropic effects that activate different cells of the innate and adaptive immunity, which altogether greatly reduced $B$. abortus infection $[14,34]$. These results demonstrated that in vivo expression of BAB1_0273 and/or BABl_0278 antigens conjugated to the SOD protein polarizes mice immunity towards a Th1-type phenotype, a fundamental response in the host cleansing process of $B$. abortus $[14,28,34]$.

Nevertheless, when we evaluated if the Th1-type immune response induced by vaccines protects $\mathrm{BALB} / \mathrm{c}$ mice challenged with pathogenic $B$. abortus 2308 strain, low protection levels were obtained, although independently BAB1_0278 ORF or sodC has provided high levels of protection $[17,18]$. These levels of protection showed the ability of $B$. abortus to counteract the development of a protective Thl immune response by impairing the secretion of IL- 12 and inhibiting T-cell activity [35] and demonstrate that the immunogenicity of antigens by themselves is essential to induce an immune response, but it is not a parameter sufficient to achieve an effective protective immunity [36]. Interestingly, if we analyze the protection trials described here, we observed a lower number of CFU in the spleen of the animals immunized with different DNA vaccines or immunized with the RB51 vaccine strain when compared to what was described in previous reports [26]. These results could be expected due 
to the great variability in the protection index (dependent variable) obtained with different DNA vaccines in BALB/c mice (independent variable), which is not yet completely standardized [37]. However, RB51-immunized mice induced approximately 1-1.5 log CFU difference in the spleen of $\mathrm{BABL} / \mathrm{c}$ mice [38], something relatively similar to what was observed in this study.

Finally, results indicated that pV273-278-sod trivalent vaccine induced higher or similar immunogenicity than pV273-sod and pV278-sod vaccines, including lymphoproliferative response, IFN- $\gamma$, and several Ig subclasses' production; nevertheless, paradoxically, this vaccine was the one conferring the lower levels of protection against the $B$. abortus 2308 strain. Therefore, we concluded that immunization with multivalent DNA vaccines encoding GI-3 BAB1_0273 or/and BAB1_0278 ORFs conjugated to the $B$. abortus sodC gene polarizes mice immunity to a Th1-type phenotype, but this immunogenicity was insufficient to induce significant levels of protection in this animal model.

\section{Conflicts of Interest}

The authors declare that they have no conflicts of interest.

\section{Acknowledgments}

This work was funded by the National Fund for Scientific and Technological Development (FONDECYT), Santiago, Chile (Grant 1130093). Leonardo Gómez is a recipient of a CONICYT scholarship for Ph.D. degree students in Chile.

\section{References}

[1] M. Durward, G. Radhakrishnan, J. Harms, C. Bareiss, D. Magnani, and G. A. Splitter, "Active evasion of CTL mediated killing and low quality responding CD8+ T cells contribute to persistence of brucellosis," PloS One, vol. 7, no. 4, Article ID e34925, pp. 1-14, 2012.

[2] Y. He, "Analyses of Brucella pathogenesis, host immunity, and vaccine targets using systems biology and bioinformatics," Frontiers in cellular and Infection Microbiology, vol. 2, no. 2, pp. $1-17,2012$.

[3] M. L. Boschiroli, S. Ouahrani-Bettache, V. Foulongne et al., "The Brucellasuis virB operon is induced intracellularly in macrophages," Proceedings of the National Academy of Sciences of the United States of America, vol. 99, no. 3, pp. 1544-1549, 2002.

[4] P. De Figueiredo, T. A. Ficht, A. Rice-Ficht, C. A. Rossetti, and L. G. Adams, "Pathogenesis and immunobiology of brucellosis review of Brucella- host interactions," American Journal of Pathology, vol. 185, no. 6, pp. 1505-1517, 2015.

[5] E. J. Young, M. R. Hasanjani Roushan, S. Shafae, R. M. Genta, and S. L. Taylor, "Liver histology of acute brucellosis caused by Brucella melitensis," Human Pathology, vol. 45, no. 10, pp. $2023-$ 2028, 2014.

[6] A. S. Dean, L. Crump, H. Greter, J. Hattendorf, E. Schelling, and J. Zinsstag, "Clinical manifestations of human brucellosis: a systematic review and meta-analysis," PLoS Neglected Tropical Diseases, vol. 6, no. 12, Article ID e1929, 2012.

[7] R. M. Roop II, J. M. Gaines, E. S. Anderson, C. C. Caswell, and D. W. Martin, "Survival of the fittest: How Brucella strains adapt to their intracellular niche in the host," Medical Microbiology and Immunology, vol. 198, no. 4, pp. 221-238, 2009.

[8] A. J. Pratt, M. DiDonato, D. S. Shin et al., "Structural, functional, and immunogenic insights on $\mathrm{Cu}, \mathrm{Zn}$ superoxide dismutase pathogenic virulence factors from Neisseria meningitidis and Brucella abortus," Journal of Bacteriology, vol. 197, no. 24, pp. 3834-3847, 2015.

[9] J. Celli, C. De Chastellier, D.-M. Franchini, J. Pizarro-Cerda, E. Moreno, and J.-P. Gorvel, "Brucella evades macrophage killing via VirB-dependent sustained interactions with the endoplasmic reticulum," Journal of Experimental Medicine, vol. 198, no. 4, pp. 545-556, 2003.

[10] Y. Ke, Y. Wang, W. Li, and Z. Chen, "Type IV secretion system of Brucella spp. and its effectors," Frontiers in Cellular and Infection Microbiology, vol. 5, no. 72, pp. 1-10, 2015.

[11] V. G. Ratushna, D. M. Sturgill, S. Ramamoorthy et al., "Molecular targets for rapid identification of Brucella spp," $B M C$ Microbiology, vol. 6, no. 13, pp. 1-22, 2006.

[12] G. G. Schurig, N. Sriranganathan, and M. J. Corbel, "Brucellosis vaccines: past, present and future," Veterinary Microbiology, vol. 90, no. 1-4, pp. 479-496, 2002.

[13] E. M. S. Dorneles, N. Sriranganathan, and A. P. Lage, "Recent advances in Brucella abortus vaccines," Veterinary Research, vol. 46, no. 76, pp. 1-10, 2015.

[14] B. Golding, D. E. Scott, O. Scharf et al., "Immunity and protection against Brucella abortus," Microbes and Infection, vol. 3, no. 1, pp. 43-48, 2001.

[15] D. Luo, B. Ni, P. Li et al., "Protective immunity elicited by a divalent DNA vaccine encoding both the L7/L12 and Omp16 genes of Brucella abortus in BALB/c mice," Infection and Immunity, vol. 74, no. 5, pp. 2734-2741, 2006.

[16] C. Zhao, Y. Sun, Y. Zhao et al., "Immunogenicity of a multiepitope DNA vaccine against hantavirus," Human Vaccines \& Immunotherapeutics, vol. 8, no. 2, pp. 208-215, 2012.

[17] A. A. Oñate, S. Céspedes, A. Cabrera et al., "A DNA vaccine encoding $\mathrm{Cu}, \mathrm{Zn}$ superoxide dismutase of Brucella abortus induces protective immunity in BALB/c mice," Infection and Immunity, vol. 71, no. 9, pp. 4857-4861, 2003.

[18] S. Céspedes, P. Salgado, A. Retamal-Díaz, R. Vidal, and A. Oñate, "Roles of genomic island 3 (GI-3) BAB1_0278 and BAB1_0263 open reading frames (ORFs) in the virulence of Brucella abortus in BALB/c mice," Veterinary Microbiology, vol. 156, no. 1-2, pp. 1-7, 2011.

[19] F. Sislema-Egas, S. Céspedes, P. Fernández, A. Retamal-Díaz, D. Sáez, and A. Oñate, "Evaluation of protective effect of DNA vaccines encoding the BAB1_0263 and BAB1_0278 open reading frames of Brucella abortus in BALB/c mice," Vaccine, vol. 30, no. 50, pp. 7286-7291, 2012.

[20] R. Riquelme-Neira, A. Retamal-Díaz, F. Acuña et al., "Protective effect of a DNA vaccine containing an open reading frame with homology to an ABC-type transporter present in the genomic island 3 of Brucella abortus in BALB/c mice," Vaccine, vol. 31, no. 36, pp. 3663-3667, 2013.

[21] E. Escalona, D. Sáez, and A. Oñate, "Immunogenicity of a multi-epitope DNA vaccine encoding epitopes from $\mathrm{Cu}-\mathrm{Zn}$ superoxide dismutase and open reading frames of Brucella abortus in mice," Frontiers in Immunology, vol. 8, no. 125, pp. 1-10, 2017.

[22] L. B. Tabatabai and G. W. Pugh Jr., "Modulation of immune responses in Balb/c mice vaccinated with Brucella abortus CuZn superoxide dismutase synthetic peptide vaccine," Vaccine, vol. 12, no. 10, pp. 919-924, 1994. 
[23] X. Chen, J. L. Zaro, and W.-C. Shen, "Fusion protein linkers: property, design and functionality," Advanced Drug Delivery Reviews, vol. 65, no. 10, pp. 1357-1369, 2013.

[24] H. C. Bimboim and J. Doly, "A rapid alkaline extraction procedure for screening recombinant plasmid DNA," Nucleic Acids Research, vol. 7, no. 6, pp. 1513-1523, 1979.

[25] L. A. Gómez, F. I. Alvarez, P. A. Fernández et al., "Immunogenicity and protective response induced by recombinant plasmids based on the BAB1_0267 and BAB1_0270 open reading frames of Brucella abortus 2308 in BALB/c Mice," Frontiers in Cellular and Infection Microbiology, vol. 6, no. 117, pp. 1-7, 2016.

[26] A. Oñate, E. Andrews, A. Beltran, G. Eller, G. Schurig, and H. Folch, "Frequent exposure of mice to crude Brucella abortus proteins down-regulates immune response," Journal of Veterinary Medicine, Series B, vol. 47, no. 9, pp. 677-682, 2000.

[27] C. L. Baldwin and R. Goenka, "Host immune responses to the intracellular bacteria Brucella: does the bacteria instruct the host to facilitate chronic infection?" Critical Reviews in Immunology, vol. 26, no. 5, pp. 407-442, 2006.

[28] P. Skendros and P. Boura, "Immunity to brucellosis," OIE Revue Scientifique et Technique, vol. 32, no. 1, pp. 137-147, 2013.

[29] J. S. Blum, P. A. Wearsch, and P. Cresswell, "Pathways of antigen processing," Annual Review of Immunology, vol. 31, no. 1, pp. 443-473, 2013.

[30] J. Hasbold, J. S.-Y. Hong, M. R. Kehry, and P. D. Hodgkin, "Integrating signals from IFN- $\gamma$ and IL- 4 by B cells: positive and negative effects on CD40 ligand-induced proliferation, survival, and division-linked isotype switching to IgG1, IgE, and IgG2a," Journal of Immunology, vol. 163, no. 8, pp. 4175-4181, 1999.

[31] A. P. M. S. Brandão, F. S. Oliveira, N. B. Carvalho et al., "Host susceptibility to Brucella abortus infection is more pronounced in IFN- $\gamma$ knockout than IL-12/ $\beta 2$-microglobulin double-deficient mice," Clinical and Developmental Immunology, vol. 2012, Article ID 589494, 7 pages, 2012.

[32] A. Martirosyan and J.-P. Gorvel, "Brucella evasion of adaptive immunity," Future Microbiology, vol. 8, no. 2, pp. 147-154, 2013.

[33] J.-P. Gorvel, “'If you bring an alarm, we will destroy it,' said Brucella to the host cell," Virulence, vol. 5, no. 4, pp. 460-462, 2014.

[34] E. A. Murphy, J. Sathiyaseelan, M. A. Parent, B. Zou, and C. L. Baldwin, "Interferon- $\gamma$ is crucial for surviving a Brucella abortus infection in both resistant C57BL/6 and susceptible BALB/c mice," Immunology, vol. 103, no. 4, pp. 511-518, 2001.

[35] W. Ahmed, K. Zheng, and Z.-F. Liu, "Establishment of chronic infection: Brucella's stealth strategy," Frontiers in Cellular and Infection Microbiology, vol. 6, no. 30, pp. 1-12, 2016.

[36] S. Mahanty, A. Prigent, and O. Garraud, "Immunogenicity of infectious pathogens and vaccine antigens," BMC Immunology, vol. 16, no. 31, pp. 1-6, 2015.

[37] T. F. Carvalho, J. P. A. Haddad, T. A. Paixão, and R. L. Santos, "Meta-analysis and advancement of brucellosis vaccinology," PLoS ONE, vol. 11, no. 11, Article ID e0166582, pp. 1-28, 2016.

[38] T. E. Todd, O. Tibi, Y. Lin et al., "Meta-analysis of variables affecting mouse protection efficacy of whole organism Brucella vaccines and vaccine candidates," BMC Bioinformatics, vol. 14, no. 6, pp. 1-13, 2013. 

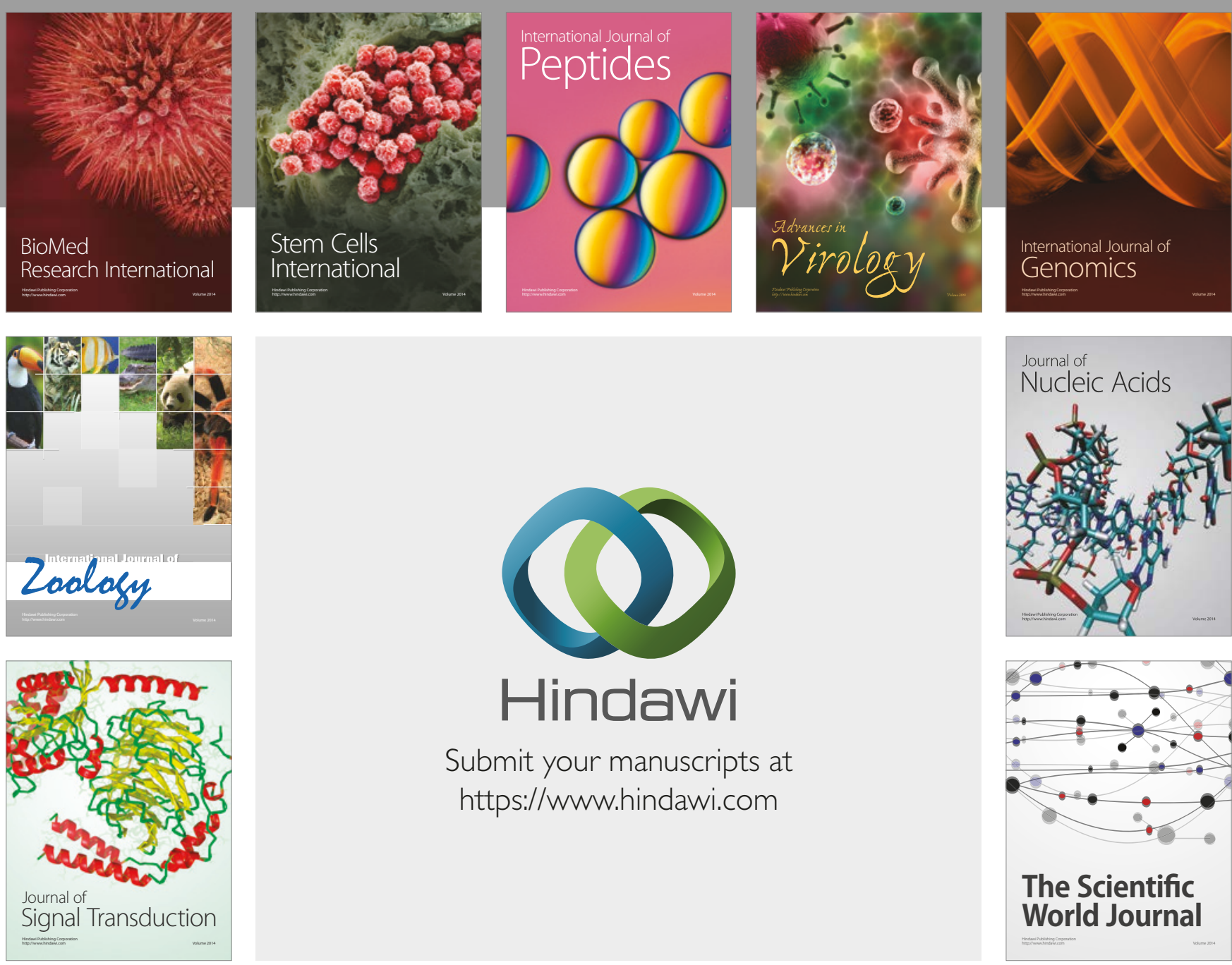

Submit your manuscripts at

https://www.hindawi.com
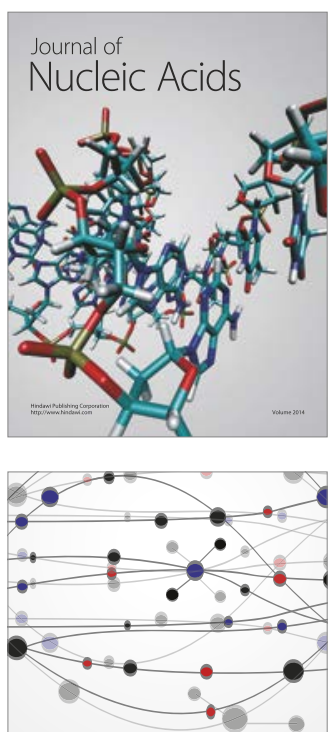

The Scientific World Journal

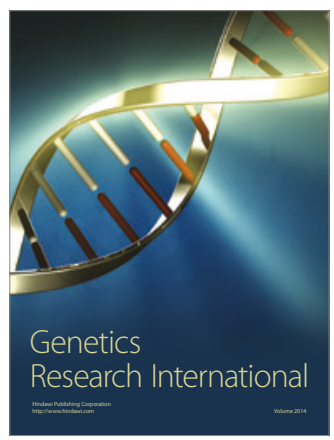



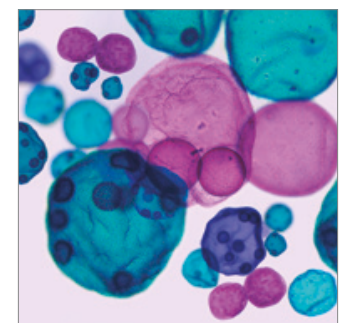

International Journal of Microbiology
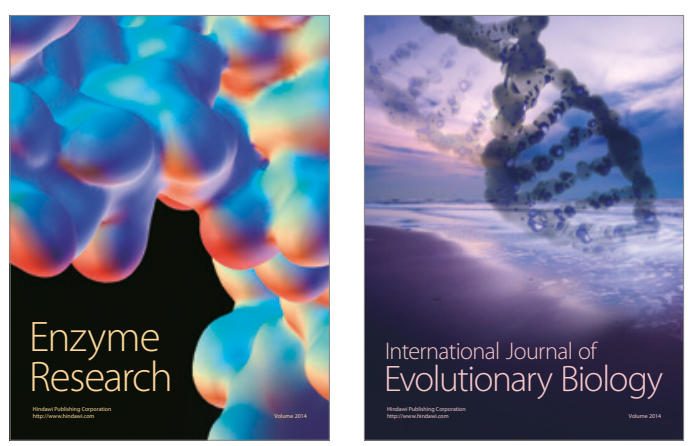


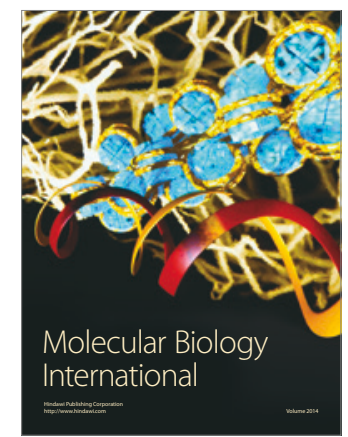



